\title{
Licensing Effect in Consumer Choice
}

\section{Uzma Khan and Ravi Dhar*}

\section{April 2005}

*Uzma Khan is a doctoral candidate at the School of Management, Yale University, 135

Prospect Street, New Haven, CT 06511, email: uzma.khan@yale.edu. Ravi Dhar is Professor at the School of Management, Yale University, 135 Prospect Street, New Haven, CT 06511, Tel: (203) 432 5947, Fax: (203) 432 3003, email: ravi.dhar@yale.edu 


\section{Licensing Effect in Consumer Choice}

Many real world choices require consumers to make decisions after other choices or judgments. We show that prior choices, which activate and boost the self-concept, are likely to subsequently license more self-indulgent choices. We propose that licensing can operate through an expression of intent to be virtuous, which reduces negative self-attributions associated with the purchase of relative luxuries. Five studies are conducted to illustrate our proposed licensing effect of expressing an initial virtuous intent on subsequent decision to be more indulgent. Consistent with our theory, the preference for an indulgent option diminishes if the licensing decision can be attributed to an external motivation. We also report a mediation analysis in support of our theoretical explanation that the licensing effect operates by providing a temporary boost in relevant self-concept. 
Imagine a person who is making a choice between two items, one of which is a relative luxury or indulgence. Is this person more or less likely to buy something more self-indulgent if she previously expressed an unrelated altruistic intent? Most choice research focuses on the decision rules by which consumers choose among a set of alternatives, independent of the manner in which they arrive at the choice. In contrast to this focus on single shot decisions, consumers in the real world often make a series of decisions where one choice follows another. Recent research suggests that preferences among alternatives might be affected systematically by consumer's prior decisions (Dhar and Novemsky 2005; Dhar and Simonson 1999). The focus of this research has been to show how prior choices might activate certain consumer goals (e.g., balancing or seeking a peak experience) that guide consistent choices. In contrast to this consistent behavior, the current research shows that prior decisions can boost individual's selfconcept that acts as a license to choose certain options. A richer analysis of consumer behavior is possible by considering the manner in which prior tasks might systematically influence the subsequent preference expression.

This article examines the hypothesis that prior expression of intent that helps establish an altruistic self-concept (e.g., compassionate and helpful person) is subsequently more likely to lead the individual to make more self-indulgent choices. We illustrate our general idea by looking at choice between options that are relative luxuries and necessities. Specifically, we hypothesize that the relative preference for a luxury option will be higher if individuals' past decisions provide a boost in their self-concept. It is useful to think of this phenomenon as a licensing effect whereby a prior intent to be virtuous boosts respondents' self-concept reducing the negative self-attributions associated with the purchase of relative luxuries. 
The paper further examines the theoretical precondition for the licensing effect. We first show that the preference for a relative luxury after expressing an initial virtuous intent is attenuated if there was an external attribution for the virtuous act. In direct support of our theory we also show that a prior virtuous decision boosts self-concept, which mediates the preference for a luxury option. Finally, we consider that consumers may not be aware of how a prior decision influences their subsequent choices. In other words, the process underlying the licensing effect may not require awareness, intention, effort, or monitoring on part of the consumer.

The findings make contributions in two important areas. First, we show how preference among a set of alternatives is systematically licensed by prior decisions. Moreover, the licensing effect occurs without explicit intention and awareness. Second, in contrast to previous research on non-conscious effects on behavior, which suggests that preferences assimilate to the salient traits or self-identity, we demonstrate that an initial altruistic intent that boosts the relevant selfconcept can liberate the individual to choose indulgent options by reducing their negative selfattributions. This has important implications more generally for understanding the effect of priming self-concept on the direction of specific choices.

The remainder of the paper is organized as follows. A brief review of prior research leads to our prediction of a systematic preference for luxury option after a prior decision that makes one appear virtuous. Next, we test our basic prediction in five experiments. Studies 1 and 2 examine the consequence of an initial licensing action by virtue of a charitable decision on the subsequent choice between a luxury and a necessity. Study 3 generalizes this effect by using a different initial task to license the participant for real choices. Studies 4 and 5 explore a boundary condition and the theoretical process underlying the licensing effect. Study 4 illustrates the effect of an external attribution manipulation, and Study 5 demonstrates that boost in self-concept 
mediates the effect on subsequent preferences. We conclude with a discussion of the theoretical and managerial implications of our findings.

\section{The Effect of Prior Decisions on Subsequent Choices}

Consumers often make a series of decisions where one choice follows another. Similarly, experience in one task can carryover and affect preference or performance in a subsequent task. Although most research has looked at choice independent of how people arrive at these choices, some recent work has used a goal-theoretic framework to understand how a prior experience or a choice might influence subsequent preferences. These papers suggest that initial actions can activate specific goals that guide subsequent choices in the direction of attaining the activated goal. For example, Dhar and Simonson (1999) show that individuals combine different items in consumption sequences in order to attain a peak experience on the goal (e.g., health or pleasure) that is activated by the choice of the first item.

In contrast to examining the effect of prior choices per se, research in social cognition has focused on the underlying cognitive processes in understanding how prior task can influence subsequent behavior. This account is based on the principle that an initial task primes certain representations that lead to the pursuit of related behaviors. The subsequent influence on behavior can occur by priming a goal or a trait (Bargh 1997). In contrast to priming of goals, a task can also prime different self-concepts that in turn influence behavior (Wheeler et al. 2005). This builds on the notion that individuals have a variety of identities, a subset of which might be salient at any given point (Turner 1987). Similar to the research on non-conscious goal or trait priming, an implicit assumption here is that preferences assimilate to the salient identity. For example, LeBoeuf and Shafir (2004) show that in a choice between Cosmopolitan and The 
Economist, people are relatively more likely to choose the latter if their scholarly identity is made salient by an initial task.

We propose that an initial choice can also serve to activate a mental construct about self. A key distinction between direct priming and choice or preference based priming is that in addition to activating a specific identity, the latter helps establish credentials for that identity by providing evidence for the activated self-concept. These credentials serve as a license to choose an option that otherwise would create negative attributions for the self. Our premise is related to Monin and Miller's (2001) results on the expression of prejudice. They demonstrated that male participants who were provided with an opportunity to establish their credentials as being nonprejudiced (e.g., by disagreeing with blatantly sexist statements) were subsequently more likely to be sexist than were male participants who first responded to more ambiguous statements about women. In a similar vein, we show that expressing an altruistic intent in an initial task is likely to activate and establish altruistic credentials and lead participants to choose, subsequently, items that are more self-indulgent.

We illustrate our predicted licensing effect of prior decision in the context of choosing between options that are perceived as either relative luxuries or necessities. While prior research in this area has used several labels somewhat interchangeably for the products (e.g., virtues and vices by Wertenbroch 1998; hedonic-utilitarian by Dhar and Wertenbroch 2000; luxury-necessity by Kivetz and Simonson 2002), a common assumption that underlies the distinction is that purchase of relative luxuries is associated with guilt and feelings of responsibility (Dahl et al. 2003; Lascu 1991). Since consumers are often looking to justify their choices (Simonson 1989), luxury goods can be at a disadvantage as they are often more difficult to justify than necessities (Okada 2005). Accordingly, the purchase of luxuries for own consumption is considered to 
produce negative self-attribution since such items are difficult to justify, induce greater guilt, and by definition, are indulgent.

Our main proposition is that engaging in or merely expressing a preference for a virtuous act leads to a boost in self-concept that increases the willingness to subsequently choose items that might otherwise lead to negative self-attribution. The intuition is similar to prior research, which shows that the purchase likelihood of a hedonic or luxury option can be enhanced by tactics that reduce the guilt or negative attributions associated with them. For example, Strahilevitz and Myers (1998) demonstrated that promised donations to charity were more effective in promoting frivolous products than in promoting practical products. In a similar vein, Kivetz and Simonson (2002) demonstrated that higher requirements of effort in the context of loyalty programs shifted people's preferences towards receiving luxury as compared to necessity rewards. They attributed this to the notion that greater effort serves as a guilt-reducing device which makes it easier to justify the purchase of luxuries. Similar to these guilt-reduction mechanism, unrelated prior intentions to act virtuously that establish positive self-attributions can license the preference for luxury items by removing their negative self-attributions.

\section{Study 1: The Effect of Altruistic Decision on Preference between Luxury and Necessity}

This study examines the effect of a prior decision that makes one appear virtuous on the subsequent preference between two items, one of which is more self-indulgent/luxury while the other is more utilitarian/necessity. We predict that in a choice between a luxury and a utilitarian option, participants would be more likely to choose the former when their past decision provides them with a license to indulge (e.g., by first providing participants with the opportunity to engage in a charitable act.) 


\section{Method}

A survey was used to identify items that are viewed as primarily luxuries or necessities. In a separate pretest, 25 participants from the same population rated two items selected from the survey, a pair of designer's jeans and a vacuum cleaner, on a nine-point scale $(1=$ utilitarian, $9=$ hedonic). Following Strahilevitz and Myers (1998), a utilitarian or a necessary item was described as one that is mainly desired to fulfill a basic need or to accomplish a functional or practical task, and a hedonic or a luxury item was described as something motivated primarily by a desire for pleasure, fantasy, and fun.

Participants in the main experiment were 108 undergraduate students at a major eastcoast university. The instructions stated that the experimenter was only interested in their opinion, and there were no right or wrong answers. Participants were randomly assigned to two conditions (license or control). In the license condition, two decisions were presented sequentially. The first problem asked them to imagine that they had volunteered to spend three hours per week doing community service. They were then shown descriptions of two community services ("Teaching children in a homeless shelter" and "Improving the environment") and were asked to choose one. Participants were also asked to state reasons for their choice to ensure their involvement in the task. After completing the first decision, participants turned to the next page where they were told to imagine that they were at a mall that was having a sale. They were then asked to choose between a pair of designer's jeans and a vacuum cleaner assuming that they had been planning to buy the two items but could only afford one at the moment. Both items were priced at $\$ 50$. Participants in the control condition only saw the second problem with the same instructions and descriptions.

\section{Results}


The pretest confirmed that the designer's jeans were seen as primarily hedonic or luxury $(\mathrm{M}=7.2)$ in relation to a vacuum cleaner $(\mathrm{M}=3.40 ; \mathrm{t}(48)=9.6, \mathrm{p}<0.01)$. We predicted that participants in the license condition would be more likely to choose the hedonic item over the utilitarian one than those in the control condition. Consistent with our prediction, significantly more people chose the designer's jeans (57.4\%) after a choice of community service than in the control condition $\left(27.7 \% ; \chi^{2}=9.7, \mathrm{p}<0.01\right)$.

The above results show that by providing participants with the opportunity to appear charitable made them subsequently relatively more likely to choose a luxury item. We proposed that the first task activates and boosts the self-concept that reduces the negative self-attributions associated with the purchase of a luxury, thereby increasing the preference for such items. Past research has used self-evaluations or self-reports to capture changes in self-concept (e.g., Heatherton and Polivy 1991; Marsh and Yeung 1998). In the same spirit, as a manipulation check, we collected participants' self-assessment on four personality traits that are likely to be relevant to whether people feel altruistic or self-indulgent, and may therefore relate to the guilt in consuming luxury options. Sixty-eight participants were assigned to a license or to a control condition. The license condition was similar to the main experiment. In the control condition, participants responded to an unrelated questionnaire where they unscrambled seven scrambled sentences (Appendix 1). All participants were then asked to indicate the extent to which they agreed or disagreed $(1=$ strongly disagree to $7=$ strongly agree $)$ with the following four statements: "I am compassionate", "I am sympathetic", "I am warm", and "I am helpful". We used these items as they exhibited a high degree of reliability in terms of coefficient alpha $($ Cronbach alpha $=0.84)$. Consistent with our theory, results in Table 1 show that participants 
rated themselves more positively on the four attributes in the license condition as compared to the control condition. All differences were significant at 5\% level.

\section{Table 1}

Mean Self-Assessment in License and Control Conditions

\begin{tabular}{llcc}
\hline \multirow{2}{*}{ am... } & & $\begin{array}{c}\text { License } \\
(\mathrm{n}=34)\end{array}$ & $\begin{array}{c}\text { Control } \\
(\mathrm{n}=34)\end{array}$ \\
\cline { 2 - 3 } & Compassionate & 5.85 & 5.17 \\
Sympathetic & 6.15 & 5.73 \\
Warm & 5.65 & 5.12 \\
Helpful & 5.50 & 5.01 \\
\hline
\end{tabular}

The next study extends the hypothesis that a prior decision that provides an opportunity to boost the self-concept licenses the choice of a relatively self-indulgent option in the following manner. First, the second choice in Study 1 was between two items that were non-comparable, which may have interacted with the processing differences in the two conditions. For example, it is possible that people consider their previous actions for guidance when the current choice is difficult (i.e., not directly comparable). Study 2 generalizes the results by demonstrating the licensing effect for items belonging to the same product category that differ in their relative perception of luxury. Second, it is possible that our results are obtained when different resources are used for the two decisions (e.g., time for first decision and money for the second). To rule this out, Study 2 demonstrates the basic effect with both choices involving a monetary outlay. Finally, given that the two choices in Study 1 were part of the same research survey, it is possible that respondents made a connection between the two tasks and their responses reflected demand effects rather than actual difference in preference. Although it is not clear why demand would predict licensing as opposed to consistency in behavior, Study 2 separated the two choices with 
an unrelated filler task to minimize the possibility that participants draw a connection between the two choice tasks.

In a second vignette described briefly, we replicate the licensing effect when the luxury option is presented in isolation. This study also asks participants' to provide reasons for their choice. If people are consciously motivated to connect the altruistic act and the indulgent option, they should be able and willing to state this motivation. In contrast, if they are unable to express or are unaware of the manner in which the first decision influences their preferences, they should not articulate its impact on preferences. More generally, this study helps us understand whether the licensing effect occurs without explicit intention, awareness, and monitoring.

\section{Study 2: The Effect of an Altruistic Choice on Preferences for Relative Luxury}

\section{Method}

Ninety-three undergraduate students at a major east-coast university participated in this experiment as part of their course requirement. As in Study 1, participants were randomly assigned to either a license or a control condition. The task instructions were similar to the first study. Participants in the license condition were presented with two decisions. In the first decision, they were asked to imagine that they have received an income tax rebate of $\$ 500$ and were thinking of donating $\$ 100$ out of this money to a charity organization. Participants were provided with a short description of the two organizations.

Following an unrelated filler task, which involved unscrambling scrambled sentences, participants made a second decision, which was the same in both conditions. Participants were asked to assume that they were thinking of buying a pair of sunglasses for themselves with part of the tax rebate money. This item was selected because Dahl et al. (2003) show that a majority 
of guilty situations arise due to purchasing frivolous or expensive items for self. A pretest indicated that sunglasses could be viewed as a luxury or as a necessity depending upon their features and price. Accordingly, participants had a choice between two sunglasses, one of which was more expensive and frivolous. For example, Sunglasses A were depicted as being superior on aesthetics, branding and on price as compared to Sunglasses B (appendix 2). A pretest confirmed that the latter was perceived as a relative necessity while the former was considered as a luxury. Participants in the control condition were also told about the tax rebate before they were asked to choose between the two sunglasses. Since our focus is on relative preference for the luxury item, this rules out an alternative account, namely that a windfall tax rebate increases the likelihood of making a more frivolous purchase (Arkes et al. 1994).

\section{Results}

We predicted that participants in the license condition would be more likely to buy the more expensive and frivolous sunglasses compared to those in the control condition. As predicted, $56.5 \%$ of participants chose to buy the expensive sunglasses after making a choice between two charities as compared to $27.7 \%$ in the control condition $\left(\chi^{2}=7.95, p<0.05\right)$. These results replicate the licensing effect shown in the first study using two alternatives from the same product class that differ in their relative perception of luxury.

We ran another vignette where the second choice presented a luxury option in isolation. The main purpose of this study was to understand whether the licensing effect occurs without explicit intention, awareness, and monitoring. As in the previous problem, participants were randomly assigned to either a license or a control condition. The main choice related to whether they would like to "buy the ticket" for a concert of their favorite artist and to give reasons for their choice. The choice results were similar to the previous studies, $45 \%$ of the participants in 
the control condition chose to buy the concert ticket while $72.5 \%$ of the participants in the license condition opted to buy the ticket $\left(\chi^{2}=6.24, p<0.05\right)$.

We also examined the explanations provided by the participants for their decision to purchase the tickets. The reasons provided were coded as follows: i) whether a reason referred explicitly to the preceding decision and ii) whether participants expressed that the preceding charitable act made them more likely to buy the concert ticket (e.g., after helping others I feel I deserve it, or I have earned it). The thought-listing analysis shows that very few of the participants in the license condition even made a connection between the two choices. Those who did not buy the ticket either considered the price to be too high or expressed a lack of interest in the event. These reasons for not buying were similar to those given by the control participants. Moreover, out of the 29 participants who did buy the concert ticket only 5 even made any reference to the prior decision. Furthermore, only 1 out of these 5 participants made the connection in the direction predicted by the theory. This respondent mentioned that "after having a productive day it's a good reason to relax". Explanations of other 4 participants did not suggest an intuition that performing community service would help with the purchase of a concert ticket "I see no connection between community service and choices in my life”, "It's not contrary to my compassion for the needy", and "There is no apparent conflict with the homeless children. As long as I feel responsible for the society I can do other things I want”. The other 24 out of 29 participants who chose to buy the ticket, gave reasons such as, "it's worth it", "why not", "It's my favorite artist", "it's a good deal”, "tickets may sell out” and "its fun". These reasons were similar to those given by participants in the control condition and did not reflect any awareness of the licensing influence of the first task. 
The studies so far used hypothetical decisions to create license as well as its effect on subsequent preferences. Note that the effect of prior hypothetical decisions is a stronger test of the licensing effect and it also helps to rule out alternative processes such as balancing or compensatory behavior across a sequence of choices (Dhar \& Simonson 1999). The next study examines if the pattern of results based on hypothetical choices are also observed with actual choices. Another possible alternative account for the effect observed in earlier studies is that respondents in the license condition expended more effort by having to make a decision prior to the choice and were therefore more likely to choose the indulgent option subsequently. To rule out a differential effort-based explanation for our findings, the next study included a task for the control participants. The difference was that the task in the control condition was not expected to boost the relevant self-concept. Also, in order to generalize beyond purchase of luxury, a different domain of expressing self-interest was used to examine the licensing effect. Participants were confronted with a real choice whether to donate all or part of the money from participating in the survey to a local charity. Finally, the licensing manipulation was modified to allow the participants an opportunity to opt out of the task. Consistent with our main proposition, we predicted that participants on average would donate less if they felt licensed by the first decision in comparison to the control condition.

\section{Study 3: Licensing Effect on Amount to Donate}

\section{Method}

Eighty undergraduate students at a major east coast university took part in the study. All participants were asked to complete two brief surveys. To ensure that participants considered the two tasks as distinct surveys, each task was presented on a separate page, in a different font, and with a different investigator listed on the top. Participants were told that they would receive a 
dollar for completing each survey. All participants agreed to complete both surveys. As in Study 1, participants were randomly assigned to two conditions (license and control). Participants in the license condition were asked to imagine that a foreign student in one of their classes had requested assistance with understanding a lecture. They were then asked to indicate whether they would be willing to help the foreign student with the course material if it required two hours of their time. After completing the first decision, participants continued to the next survey. The second survey, which served as a filler task, was the same scrambled sentence task as used in earlier studies. On completing the two tasks, participants were handed two dollars. After getting paid participants were asked if they would like to donate any of this amount to a local charity. Participants had to indicate the amount they would be willing to donate from $\$ 0$ to $\$ 2$. Finally, participants were questioned about the real purpose of the study. None of the participants correctly guessed the main purpose of the study. In the end, each participant was debriefed and received the full payment. The first task in the control condition had participants identify words that were misspelled in a passage of text (Appendix 3). Next, participants performed the same sentence unscrambling task and then indicated the amount they would donate to the local charity.

\section{Results}

We predicted that providing participants an opportunity to help a foreign student would increase the amount of money that they kept for themselves. First, all participants in the licensing condition opted to help the foreign student. The data show that the number of participants who donate after helping a foreign student (87.5\%) is not significantly different from the number of participants who donate after identifying misspelled words $\left(92.5 \% ; \chi^{2}=0.556, \mathrm{p}=n s\right)$. We speculate that perhaps participants in both the conditions felt obligated to donate something to the charity and therefore most participants made a donation. However, consistent with our 
prediction, among those who donated, donations were significantly less in the licensing condition $(\mathrm{M}=1.2)$ in comparison to the control condition $(\mathrm{M}=1.7 ; \mathrm{t}(70)=2.73, \mathrm{p}<0.01)$.

As stated previously, the opportunity to express an altruistic intent in the initial task boosts respondents' self-concept, which reduces negative self-attributions associated with selfindulgent choices. To support this premise, we collected self-assessment on the same four personality traits as used in Study 1 from a separate group of thirty participants assigned to the same two conditions. Participants in the licensing condition were presented with the opportunity to help a foreign student while in the control condition they were presented with the task to identify misspelled words. Consistent with our theory, results in Table 2 show that participants rated themselves more positively on the four attributes in the condition where they initially expressed an intent to help a foreign student as compared to the control condition where they picked out misspelled words in a passage of text. All differences were significant at $5 \%$ level.

Table 2

Mean Self-Assessments

\begin{tabular}{ccc}
\hline I am... & $\begin{array}{c}\text { Help a foreign } \\
\text { student } \\
(\mathrm{n}=15)\end{array}$ & $\begin{array}{c}\text { Identify } \\
\text { misspelled words } \\
(\mathrm{n}=15)\end{array}$ \\
\cline { 2 - 3 } Compassionate & 5.9 & 5.1 \\
Sympathetic & 6 & 5.1 \\
Warm & 5.8 & 4.9 \\
Helpful & 6.2 & 5 \\
\hline
\end{tabular}

The findings so far support our hypothesis that an initial task that boosts the self-concept subsequently licenses choosing a relatively self-indulgent option. Study 1 demonstrated our basic hypothesis for a choice between a relative luxury and a necessity. Study 2 generalized the main hypothesis for items belonging to the same product category that differed in their relative perception of luxury. Study 3 demonstrated that the results based on hypothetical choices are 
also observed with actual choices and in a different domain. Moreover, the findings so far suggest that participants might be unaware of the license from a prior decision and its consequence for subsequent preference. When asked reasons for their choice, participants were unable to articulate the impact of the licensing act on their subsequent preferences. What is probably more relevant is the phenomenological state of the respondents that makes it easier to choose an option that otherwise would cause negative self-attributions. Previous research has suggested that the diagnosticity of the subjective experience can be modified by attribution manipulations (Schwarz and Clore 1983). The next study directly tests for this change in the subjective state to influence the choice likelihood. As shown by Schwarz and Clore (1983), the subjective experience can be manipulated through an attribution manipulation even when one is not aware of the link between a subjective state and its effect on subsequent action. Study 4 shows that attributing one's virtuous intent to an external source is unlikely to boost the relevant self-concept and provide a license for subsequent indulgent preference.

\section{Study 4: The Effect of Attribution Manipulation on the Licensing Effect}

\section{Method}

One hundred and twenty undergraduate students took part in the study as a course requirement. Participants were randomly assigned to three conditions. The first two conditions were the same as in Study 1. In the first condition, referred to as the licensing condition, participants were presented with two tasks sequentially. The first problem asked them to imagine that they have decided to volunteer four hours per week for six weeks doing community service and were choosing between teaching children and improving the environment. After expressing their intent, participants completed a filler task requiring them to unscramble scrambled 
sentence. Participants then turned to the next task where they chose between a pair of designer's jeans and a vacuum cleaner (same as in Study 1).

The second condition, referred to as the external-attribution condition, was the same as the licensing condition except that participants were provided with an external motivation for performing the community service. Specifically, they were told to imagine that they had been asked by their traffic police department to do four hours of community service for six weeks for having committed a driving violation. Participants then chose from the same two community service options. After a filler task they chose between the designer's jeans and the vacuum cleaner. Participants in the control condition first performed a filler task and then saw the second choice between the designer's jeans and the vacuum cleaner.

\section{Results}

The licensing effect was replicated. That is, in comparison to the control condition (40\%), significantly more participants opted for the designer jeans in the licensing condition when no external attribution was provided $\left(62 \% ; \chi^{2}=4.05, \mathrm{p}<0.05\right)$. We predicted that attributing the altruistic intent to an external cause through an attribution manipulation would attenuate the licensing effect. Consistent with our hypothesis, when participants selected a charity as a penalty for driving violation only $45 \%$ chose the designer's jeans in the second choice, which is not significantly different from the proportion in the control condition $\left(\chi^{2}=0.2, \mathrm{p}=n s\right)$.

The results so far show that the likelihood of choosing a more self-indulgent option increases if licensed by an initial task. We also provide some evidence that the initial altruistic decision provides a boost in relevant self-concept, which we suggest licenses the selection of an option that is associated with negative self-attributions. Moreover, the explanations provided for their choice suggests that participants were unaware of the licensing effect of their initial 
decision. Study 4 demonstrated that attributing the licensing decision to an external cause through an attribution manipulation dampens the effect. Despite demonstrating the licensing effect and its boundary, the studies so far did not provide a direct observation of the proposed underlying process. The next study tests for mediation of the changing self-concept on the willingness to choose a more indulgent item.

\section{Study 5: Mediating Effect of a Boost in Self-Concept on Relative Preference for Luxury}

\section{Method}

Sixty-six undergraduate students were randomly assigned to either a license or a control condition. Participants in the license condition first expressed their intent between two community services (as in Study 1), while those in the control condition responded to an unrelated questionnaire of similar length and intensity. After a short filler task, participants in both conditions were asked to indicate the extent to which they agreed or disagreed $(1=$ strongly disagree, 7 = strongly agree) with the four self-assessment statements used as manipulation check in Study 1; "I am compassionate", "I am sympathetic", "I am warm", and "I am helpful". To minimize guessing, the self-assessment scale described in Study 1 was embedded in a series of other irrelevant scales. Finally, after a second filler task, all participants indicated their relative preference for a pair of designer's jeans and the vacuum cleaner on a scale from 1-7 $(1=$ most likely to buy the vacuum cleaner and $7=$ most likely to buy the designer jeans - scale in

appendix 4).

\section{Results}

The ratings on the four self-assessments were averaged to form a self-concept scale that was highly reliable (Cronbach's alpha $=0.95)$. As predicted, participants rated themselves more 
positively in the license condition $(\mathrm{M}=5.76)$ than in the control condition $(\mathrm{M}=4.79 ; \mathrm{t}(64)=$ 2.31, $\mathrm{p}<0.05)$. Also, consistent with the previous studies, the choice data replicated the licensing effect. The relative reference for the hedonic designer's jeans was significantly higher in the license condition $(M=5.9)$ than in the control condition $(M=5.4 ; t(64)=2.27, p<0.05)$.

We test for the mediating effect of boost in self-concept (mediator variable) on preference for the hedonic alternative (outcome variable) as per Baron and Kenny (1986). In order to show mediation, three effects must hold. 1) The independent variable (license) must have an effect on the mediator variable (Self-Concept). 2) The independent variable (license) must have an effect on the outcome variable (preference). 3) When preference is regressed on both the mediator and the independent variable the effect of the independent variable must be weaker than when it is by itself. Our data satisfy the three criteria for a mediation model noted above. First, self-concept was significantly enhanced in the license condition than in the control condition $(\beta=0.25, \mathrm{p}<0.05)$. Second, the average preference for the designer's jeans was higher in the license condition than in the control condition $(\beta=0.24, \mathrm{p}<0.05)$. Finally, when Preference was regressed on both license and self-concept the effect of license was no more significant $(\beta=0.10, \mathrm{p}=n s)$, while the effect of self-concept was significant $(\beta=0.56, \mathrm{p}<0.01)$. The results of the mediation analysis are consistent with the notion that an initial virtuous choice boosts self-concept, which in turn increases preference for the relative luxury option.

\section{GENERAL DISCUSSION}

Consumer choice research has focused mainly on isolated or single-shot choices. In contrast, consumers arrive at decisions after having made other decisions. This paper examines how an initial intent licenses subsequent choices through changes in self-concept in the context 
of choosing between a relative luxury and a necessity. The purchase of relative luxuries, which is often associated with negative self-attributions such as self-indulgence and guilt (Dahl et al. 2003; Okada 2005), can be licensed by unrelated prior choices. We propose that a boost in selfconcept from expressing an altruistic intent can reduce the negative self-attributions associated with luxury items and hence increase their purchase incidence.

Our results consistently demonstrate that choice of a more hedonic option increases after an initial licensing action. Study 1 illustrates that participants were more likely to choose a relative luxury after an initial license generating decision. Study 2 extends the main results to a choice from the same product class. Participants were more likely to choose the more expensive and frivolous option when they first made a decision about community service. An analysis of participants' explanations suggests that they were not aware of the effect of their previous decision on their subsequent choices. Study 3 extends these results for a real decision and to a different domain. Participants were likely to donate a lower amount to charity after expressing a decision to help a foreign student.

These studies illustrated our hypothesized licensing effect on subsequent preference for luxury items. We proposed that the licensing decision provides a boost in self-concept, which subsequently increases preference for relative luxuries by dampening the negative selfattributions associated with the purchase of such items. Supporting our explanation, Study 4 shows that the effect of a previous choice is moderated if the licensing act is attributed to an external motivation. Finally, Study 5 directly shows that a boost in self-concept from the licensing act mediates the preference for luxury.

\section{Theoretical Contributions}


The licensing effect operates in a similar fashion to other guilt-reducing mechanisms, such as those proposed by Strahilevitz and Myers (1998) and Kivetz and Simonson (2002). These articles show that guilt-reducing mechanisms, such as donating to a charity or expending more effort, can increase the preference for a luxury item. Our proposition shows how the expression of prior unrelated intent can influence subsequent preferences. We explain the licensing effect in terms of an increase in positive self-concept, which decreases the negative self-attributions associated with a luxury item and hence increases its choice likelihood.

A related account could be based on the notion of balancing or compensation among choices (Dhar and Simonson 1999). It is possible that participants are motivated to alternate decisions in a sequence that allows them to enjoy a luxury item after doing a noble act. That is, they may (consciously) choose the relative luxury because they feel more deserving after a charitable decision. Note that balancing as a meta-cognitive decision strategy implies awareness and no effect on self-concept. While relatively little is known about the precise mechanism through which balancing operates, the two mechanisms can be quite similar if one assumes a boost in self-concept from the first decision, and that the influence of self-concept change can occur outside of conscious awareness or monitoring. A second potential difference is that the license can be based on an action that is not highly diagnostic. This is especially the case in the current set of studies where selecting a charity in a hypothetical forced choice cannot be viewed as truly diagnostic of one's self. Yet such participants reported an increase in self-assessment and showed the licensing effect. This suggests that self-signaling can work by merely expressing an intent and in a manner different from that generally assumed in economics of information.

A conceptually different account of how prior decisions might influence subsequent preferences could be based on mental or actual resource depletion (e.g., Muraven and Baumeister 
2000). According to this account, the extent to which the first choice depletes one's limited selfcontrol resource might make it more difficult to resist a subsequent temptation to indulge. A resource-depletion account deserves further study but is unlikely to apply to the current set of studies for a number of reasons. First, we find support for our proposed theoretical mechanism; that an initial choice between two charitable acts boosts self-concept. Second, it is uncertain whether simple hypothetical decisions are resource depleting.

An alternative account for our proposed results could be based on affect. It may be argued that performing an altruistic act induces good mood which increases preference for relative luxuries. We do not think affect explains the current results. First, because we find support for our underlying process (i.e., change in self-concept) and second because mood does not generate systematic sharp predictions. For example, according to mood-maintenance paradigm, likelihood of luxury consumption should be higher after virtues since people may seek to maintain the good mood induced by the prior choice. On the other hand, an argument can also be made for mood elevation; that is, one may seek to improve a bad mood resulting from forced charity work by choosing a more hedonic item. We also did not find any evidence that the first task elevates the general mood. We measured affect in the control and the license condition (after choosing a charity). Participants stated how they felt at the moment on a four-item, seven-point mood scale (Lee and Sternthal 1999) that was anchored by: sad-happy, bad mood-good mood, irritable-pleased, and depressed-cheerful $(1=$ most negative and $7=$ most positive; appendix 5$)$. There was no significant difference in the mood scores of the license $(M=21)$ and the control conditions $(\mathrm{M}=20.15 ; \mathrm{t}(78)=0.67, \mathrm{p}=n s)^{1}$, suggesting that responding to charity task did not cause a significant elevation in participants' moods.

\footnotetext{
${ }^{1}$ Ratings on the four mood items were summed to form a single index.
} 


\section{Directions for Future Research}

Our results generate several opportunities for future research. We focused on the effect of activating and boosting self-concept on preference for relative luxuries. Future research could further examine other type of choices that benefit from an initial altruistic decision. Our results built on the notion that the first choice helps reduce the negative attributions which licenses the second choice. It is likely that the licensing effect will not occur when the subsequent choice can redefine the motive for the earlier decision. For example, a moderately religious individual who sometimes goes to religious services and sometimes eats pork might be less, and not more, likely to eat pork on the day she visits the synagogue than on a day that she does not. Rather than reducing the guilt from consuming pork, the thought of eating pork after visiting the synagogue might redefine the initial act of going to the service. Resolving when and which prior intents serve as a license rather than guide consistent subsequent behavior provides an important agenda for future research.

Another interesting question relates to the effect of different priming mechanisms on behavior. In contrast to choice-based primes, other priming methods generally produce preferences that assimilate to the active self (LeBoeuf and Shafir 2004). A question that naturally arises at this point is when preferences will assimilate to the active self and when will they contrast. One notable difference in the current research and LeBoeuf and Shafir (2004) is that unlike their methodology, which merely activates an identity through priming, choice-based primes require an active participation through a choice. We speculate that such active participation may cause the subsequent choices to move away from the salient self-concept if the other action is also desirable.

\section{Marketing Implications}


The findings of this research provide some general guidelines for marketing of relative luxuries. The negative self-attributions associated with the purchase and consumption of luxury products often lead the marketers to frame their products as a necessity. For example, Lexus attempts to alleviate the difficulty involved in paying for a luxury car by advertising itself as "we shouldn't call them luxury vehicles - luxury is something you can live without". Our findings suggest that marketers of luxury goods can reduce the negative self-attributions of luxury consumption by highlighting other decisions made by consumers that are likely to boost their self-concept. Such a mechanism to increase preference for luxury items does not require people to consciously link the source of enhanced self-concept with the choice of the luxury product being marketed. In fact, a direct link might prove counterproductive by making the motives of both the marketer and consumer transparent.

The implications are greater for online shopping environment or catalogs where marketers have greater control over the sequence of processes prior to the purchase decision. For example, online retailers of relative luxuries might increase choice incidence by influencing the relevant self-concept by providing an opportunity for people to volunteer for multiple causes. Specifically, providing consumers with the opportunity to perform licensing acts before browsing might increase the likelihood of purchase. In general, as marketers continue to learn how their customers are influenced by prior decisions, they will be better able to influence the underlying preferences. 


\section{$\underline{\text { Appendix } 1}$}

\section{INSTRUCTIONS}

Please put the following scrambled sentences in order.

1. game is greatest baseball earth the on CORRECT ORDER:

2. that is my not satchel new CORRECT ORDER:

3. party birthday have big a can they CORRECT ORDER:

4. I that were wouldn't if you eat I CORRECT ORDER:

5. video Alan recently presentation viewed by I a 


\section{$\underline{\text { Appendix } 2}$}

\begin{tabular}{|l|l|}
\hline \multicolumn{1}{|c|}{ Sunglasses A } & \multicolumn{1}{c|}{ Sunglasses B } \\
\hline - Italian designers frames & - American frames \\
- Highly resistant to scratch and impact & - Resistant to moderate impact and scrape \\
- Ultra lightweight with adjustable & - Regular weight with fixed temples and \\
temples and nose pads & nose pads \\
- Average customer rating & - Average customer rating thithth \\
- Price $=\$ 110$ & - Price $=\$ 69$ \\
\hline
\end{tabular}

$\begin{array}{lll}\text { Please circle your choice: } & \text { A) Buy Sunglasses A } & \text { B) Buy Sunglasses B }\end{array}$ 


\section{$\underline{\text { Appendix } 3}$}

$\underline{(\text { Principal investigator }=Y Y)}$

\section{INSTRUCTIONS}

Please carefully read the following passage and identify the words that are not spelled right. Circle every word that is not spelled correctly.

Abebe Bikila was born in 1932 in the twon of Jato, Ethiopia. He was one of the children in a large, poor family, so he went to school for a while and then went to work as a shephard. When he was 17 years old, he anlisted in his countries army. Later, he became a member of the Immperial Guard. There he got the chance to participate in athletic competitions. He worked with a trainner named Onni Niskanen, who was from Sweden. Niskanen thought that Bikila's running time might improve if he ran in athletic shoes made with vacum technology.

How many words were misspelled?

How confident are you that you detected all the misspelled words?

Very confident

Somewhat confident

Not at all confident 


\section{$\underline{\text { Appendix } 4}$}

Most likely $\quad$ 1--|-|--|--|--2--|-|--|-|--3--|--|-|-|--4--|-|--|-|--5--|-|--|-|--6--|--|-|--|-7 Most likely To buy the to buy the vacuum cleaner designer's jeans 


\section{References}

Arkes, Hal R., Cynthia A. Joyner, Mark V. Pezzo, Jane Gradwohl Nash, Karen Siegel-Jacobs and Eric Stone (1994), “The Psychology of Windfall Gains,” Organizational Behavior and Human Decision Processes, 59 (September), 331-47.

Bargh, John A. (1997), "The Automaticity of Everyday Life," in The Automaticity of Everyday Life: Advances in Social Cognition, Vol. 10, Robert S. Wyer, Jr., eds. Mahwah, NJ: Erlbaum.

Baron, Robert M. and David A. Kenny (1986), "The Moderator-Mediator Distinction in Social Psychological Research: Conceptual, Strategic, and Statistical Considerations," Journal of Personality and Social Psychology, 51 (December), 1173-82.

Dahl, Darren W., Heather Honea and Rajesh V. Manchanda (2003), “The Nature of SelfReported Guilt in Consumption Contexts,” Marketing Letters, 14 (October), 159-171.

Dhar, Ravi and Itamar Simonson (1999), "Making Complementary Choices in Consumption Episodes: Highlighting Versus Balancing," Journal of Marketing Research, 36 (February), 2944.

---- and Klaus Wertenbroch (2000), “Consumer Choice Between Hedonic and Utilitarian Goods," Journal of Marketing Research, 37 (February), 60-71. 
---- and Nathan Novemsky (2005), "Goal Fulfillment and Goal Targets in Sequential Choice," Journal of Consumer Research (Forthcoming).

Heatherton, Todd F. and Janet Polivy (1991), "Development and Validation of a Scale for Measuring State Self-Esteem," Journal of Personality and Social Psychology, 60 (June), 895910

Kivetz, Ran and Itamar Simonson (2002), "Earning the Right to Indulge: Effort as a Determinant of Customer Preferences towards Frequency Program Rewards," Journal of Marketing Research, 39 (May), 155-70.

Lascu, Dana N. (1991), “Consumer Guilt: Examining the Potential of a New Marketing Construct," in Advances in Consumer Research, Vol. 18, Rebecca Holman and Michael Solomon, eds. Provo, UT: Association for Consumer research, 290-93.

LeBoeuf, Robyn and Eldar Shafir (2004), “Alternating Selves and Conflicting Choices: Identity Salience and Preference Inconsistency,” Working paper, University of Florida.

Lee, Angela Y. and Brain Sternthal (1999), “The Effect of Positive Mood on Memory,” Journal of Consumer Research, 26 (September), 115-127. 
Marsh, Herbert W. and Alexander Seeshing Yeung (1998), “Top-Down, Bottom-Up, and Horizontal Models: The Direction of Causality in Multidimensional, Hierarchical Self-Concept Models," Journal of Personality and Social Psychology, 75 (August), 509-27.

Monin, Benoit and Dale T. Miller (2001), "Moral Credentials and the Expression of Prejudice," Journal of Personality and Social Psychology, 81 (July), 33-43.

Muraven, Mark and Roy F. Baumeister (2000), "Self-Regulation and Depletion of Limited Resources: Does Self-Control Resemble a Muscle?” Psychological Bulletin, 126 (March), 24759.

Okada, Erica M. (2005), “Justification Effects on Consumer Choice of Hedonic and Utilitarian Goods," Journal of Marketing Research, 42 (February), 43-53.

Schwarz, Norbert and Gerald L. Clore (1983), "Mood, Misattribution, and Judgments of WellBeing - Informative and Directive Functions of Affective Sates," Journal of Personality and Social Psychology, 45 (September), 513-23.

Simonson, Itamar (1989), “Choice Based on Reasons - The Case of Attraction and Compromise Effect," Journal of Consumer Research, 16 (September), 158-74. 
Strahilevitz, Michael and John G. Myers (1998), "Donations to Charity as Purchase Incentives: How Well They Work May Depend on What You Are Trying to Sell," Journal of Consumer Research, 24 (March), 434-46.

Turner, John C. (1987), “A Self-Categorization Theory,” in Rediscovering the social group, Turner et al., eds. Oxford and New York: Basil Blackwell.

Wertenbroch, Klaus (1998), “Consumption Self-Control by Rationing Purchase Quantities of Virtue and Vice," Marketing Science, 17 (4), 317-37.

Wheeler, Christian S., Kenneth G. DeMarree and Richard E. Petty (2005), "The Roles of the Self in Priming-to-Behavior Effects," in A. Tesser, J. V. Wood, \& D. A. Stapel (Eds.), On building, defending, and regulating the self: A psychological perspective (pp. 245-271). New York: Psychology Press 